\title{
IMPLEMENTASI ALGORITMA DIJKSTRA DALAM PENCARIAN RUTE TERPENDEK TEMPAT WISATA DI KABUPATEN KLATEN
}

\author{
NUGROHO ARIF SUDIBYO ${ }^{1}$, PERMADI EKA SETYAWAN ${ }^{2}$, YOHANA PUTRA SURYA \\ RAHMAD HIDAYAT ${ }^{3}$ \\ ${ }^{1}$ Universitas Duta Bangsa, Jl. Bhayangkara Tipes Serengan Kota Surakarta 57154 \\ nugroho_arif@udb.ac.id \\ ${ }^{2}$ Universitas Duta Bangsa, Jl. Bhayangkara Tipes Serengan Kota Surakarta 57154 \\ permadieka46@gmail.com \\ ${ }^{3}$ Sekolah Menengah Kejuruan Negeri 2 Kudus \\ yohan.artup@gmail.com
}

First Received: 09-03-2020; Accepted: 28-04-2020

\begin{abstract}
Abstrak
Wisata air adalah salah satu jenis wisata unggulan yang ada di Klaten, umumnya wisata air di Klaten adalah objek wisata untuk pemandian umum. Dalam pengambilan jalur untuk memudahkan bagi wisatawan lokal maupun mancanegara, ini sangat diperlukan untuk mencari jalur tercepat menuju salah satu titik wisata air. Dalam artikel ini akan dibahas bagaimana penerapan algoritma Dijkstra dalam mencari rute terpendek pada pencarian objek wisata di Kabupaten Klaten dengan bantuan program Tora. Hasil penelitian menunjukkan terdapat sepuluh jalur terpendek dengan titik awal Terminal Delanggu.
\end{abstract}

Kata kunci: Rute terpendek; Algoritma Dijkstra; Klaten

\section{IMPLEMENTATION DIJKSTRA ALGORITHM IN SEARCHING THE SHORTEST PATH TOURISM ROUTE IN KLATEN DISTRICT}

\begin{abstract}
Water tourism is one of the leading types of tourism in Klaten, generally, water tourism in Klaten is a tourist attraction for public baths. In taking the route to make it easier for local and foreign tourists, it is very necessary to find the fastest path to one of the water tourism points. In this paper, we will discuss how the application of the Dijkstra algorithm in finding the shortest route in the search for attractions in Klaten Regency with the help of Tora software. The results showed that there were ten shortest paths with Terminal Delanggu starting point.
\end{abstract}

Keywords: Shortest path; Dijkstra algoritm; Klaten 


\section{PENDAHULUAN}

Pada tahun 1959 pelopor komputasi, Edsgar Dijkstra, mengembangkan algoritma untuk menemukan jalur terpendek antara titik awal dan titik akhir dalam grafik berbobot di mana semua bobot positif (Yusuf, Az-zahra, \& Apriyanti, 2017). Ini agak mirip dengan algoritma Prim dalam hal itu bekerja keluar dari titik awal, menambahkan simpul dan tepi satu per satu untuk membangun pohon T. Namun, ini berbeda dari algoritma Prim dalam cara memilih simpul berikutnya untuk ditambahkan, memastikan bahwa untuk setiap simpul yang ditambahkan, panjang jalur terpendek dari $a$ ke $v$ telah diidentifikasi (Fitria \& Triansyah, 2013).

Pada awal pelaksanaan algoritma, setiap simpul $u$ dari $G$ diberi label $L(u)$, yang menunjukkan perkiraan terbaik saat ini dari panjang jalur terpendek dari $a$ ke $u$ (Wang, 2012). $L(a)$ awalnya diset sama dengan 0 karena jalur terpendek dari $a$ ke $a$ memiliki panjang nol, tetapi, karena tidak ada informasi sebelumnya tentang panjang jalur terpendek dari $a$ ke simpul $G$ lainnya, label $L(u)$ dari setiap simpul $u$ selain $a$ pada awalnya diatur sama dengan angka, dilambangkan $\infty$, yang lebih besar dari jumlah bobot semua tepi G. Saat eksekusi algoritma berlangsung, nilai $L(u)$ diubah, akhirnya menjadi panjang sebenarnya dari jalur terpendek dari $a$ ke $u$ di $G$ (Ardyan, Suyitno, \& Mulyono, 2017).

Seperti halnya algoritma Kruskal dan Prim untuk menemukan pohon rentang minimum, ada cara sederhana namun tidak efisien untuk menemukan jalur terpendek dari $a$ ke $z$ : menghitung panjang semua jalur dan memilih satu yang terpendek. Masalahnya adalah bahwa bahkan untuk grafik yang relatif kecil menggunakan metode ini untuk menemukan jalur terpendek dapat memerlukan miliaran tahun, sedangkan algoritma Dijkstra dapat melakukan pekerjaan dalam beberapa detik (Retnani, Istiadi, \& Roqib, 2015; Sholihah, 2015; Harahap \& Khairina, 2017).

Wisata air adalah salah satu jenis wisata unggulan yang ada di Klaten, umumnya wisata air di Klaten adalah objek wisata untuk pemandian umum. Wisata ini kebanyakan berada di wilayah yang mempunyai sumber mata air sendiri, misalnya wilayah Cokro, Polanharjo dan Janti. Untuk pengunjung yang berdatangan terdiri dari berbagai daerah bahkan ada yang dari mancanegara. Dalam pengambilan jalur untuk memudahkan bagi wisatawan lokal maupun mancanegara, ini sangat diperlukan untuk mencari jalur tercepat menuju salah satu titik wisata air, hal ini dapat memudahkan wisatawan dalam pencarian jalur dan hal ini juga dapat membuat pertambahan wisatawan yang akan datang ke wisata air yang ada di Klaten. Oleh karena itu, dalam makalah ini akan dibahas bagaimana penerapan algoritma Dijkstra dalam 
mencari rute terpendek pada pencarian objek wisata di Kabupaten Klaten dengan perhitungan manual dan dengan bantuan program Tora.

\section{METODE PENELITIAN}

Pada penelitian ini data yang digunakan adalah data sekunder yang didapat dari Google Maps yaitu data jarak antar objek wisata di Kabupaten Klaten yaitu Cokro, Umbul Ponggok, Umbul Besuk, Umbul Nilo, Umbul Sigedang, Wisata Air Water Gong Polanharjo, Umbul Manten, Umbul Pelem Water Park, Umbul Gedhe dan Wisata Siblarak. Akan digunakan langkah-langkah berikut untuk memecahkan suatu permasalahan.

1. Memformulasikan persoalan yang terjadi di Kabupaten Klaten yaitu bagaimana rute terpendek yang dimulai dari Terminal Delanggu yaitu dengan mengasumsikan titik sebagai objek wisata dan garis sebagai jalur yang ditempuh antar objek wisata.

2. Memformulasikan model matematis dari persoalan jarak terpendek yang harus dilalui yaitu dengan matematika diskrit dengan Algoritma Djikstra.

3. Membuat rute terpendek antar objek wisata dengan Algoritma Djikstra dihitung secara manual dan dengan software Tora dengan titik awal Terminal Delanggu.

4. Mengimplementasikan hasil studi dengan menentukan rute terpendek dari titik awal Terminal Delanggu ke sepuluh objek wisata di Klaten.

\section{Algorithm Dijkstra}

Notasi dan terminologi mengacu pada (EPP, 2011; Prajapati, Singhal, Ranjan, \& Chourasia, 2017).

Input: $G$ [graf sederhana yang terhubung dengan bobot positif untuk setiap sisi], $\infty$ [angka lebih besar dari jumlah bobot semua sisi dalam graf], $w(u, v)$ [bobot sisi $\{u, v\}$ ], $a$ [titik awal], $z$ [titik akhir]

\section{Algoritma:}

1. Inisialisasi $T$ adalah suatu graf dengan simpul $a$ dan tanpa sisi. Misalkan $V(T)$ adalah himpunan titik $T$, dan biarkan $E(T)$ adalah himpunan sisi $T$.

2. Misalkan $L(a)=0$, dan untuk semua titik dalam $G$ kecuali $a$, misalkan $L(u)=\infty$.

3. Inisialisasi $v$ sama dengan $a$ dan $F$ menjadi $\{a\}$.

4. $\operatorname{sementara}(z \in V(T))$

a. $F:=(F-\{v\}) \cup\{$ simpul yang berdekatan dengan $v$ dan tidak dalam $V(T)\}$ 
b. Untuk setiap titik $u$ yang berdekatan dengan $v$ dan tidak dalam $V(T)$, if $L(v)+w(v, u)<$

$$
\begin{gathered}
L(u) \text { then } L(u):=L(v)+w(v, u) \\
D(u):=v
\end{gathered}
$$

c. Temukan titik $a$ dalam $F$ dengan label terkecil

Tambahkan titik $x$ pada $V(T)$, dan tambahkan sisi $\{D(x), x\}$ to $E(T)$

$$
v:=x
$$

berakhir sementara

Output: $L(z)$

\section{HASIL DAN PEMBAHASAN}

Dalam penelitian ini, tempat wisata diasumsikan sebagai titik, dan jarak antar tempat wisata diasumsikan sebagai sisi yang memiliki bobot. Hasil penelitian yang telah diperoleh berupa nama tempat wisata dapat dilihat pada Gambar 1 dan Tabel 1. Data penelitian ini diambil dari Google Maps.

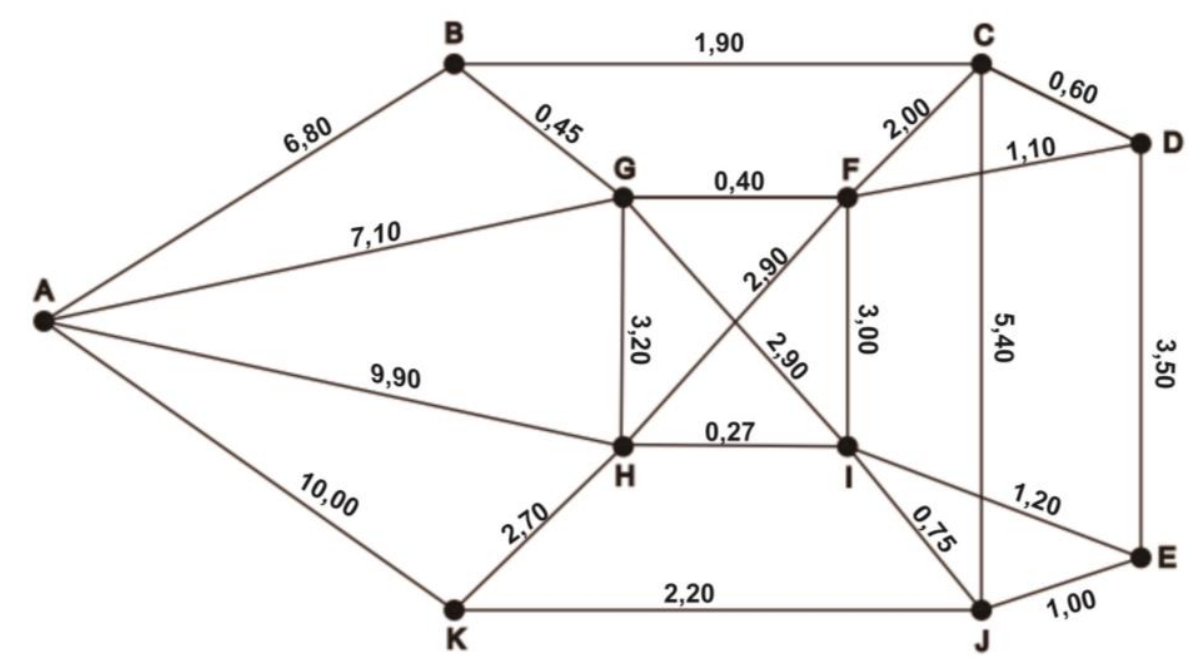

Gambar 1. Wisata air yang ada di Klaten

Tabel 1. Kode huruf dengan keterangan tempat wisata air yang ada di Klaten

\begin{tabular}{cl}
\hline Huruf & \multicolumn{1}{c}{ Keterangan } \\
\hline A & Terminal Delanggu \\
B & Objek Wisata Mata Air Cokro \\
C & Umbul Ponggok \\
D & Umbul Besuki \\
E & Umbul Nilo \\
F & Umbul Sigedang \\
G & Wisata Air Water Gong Polanharjo \\
H & Umbul Manten \\
I & Umbul Pelem Water Park \\
\hline
\end{tabular}


Riemann Volume 2, No. 1, April 2020, hal. 1-9

\begin{tabular}{cl}
\hline $\mathbf{J}$ & Umbul Gedhe \\
$\mathbf{K}$ & Wisata Siblarak \\
\hline
\end{tabular}

Hasil penelitian berupa jarak antar tempat wisata di Kabupaten Klaten disajikan pada Tabel 2.

Tabel 2. Rute terpendek tempat wisata air yang ada di Klaten dengan representasi titik dan garis

\begin{tabular}{lcccc}
\hline No. & Gambar & Tujuan & Rute & Jarak \\
\hline 1. & $0^{\text {A (root) }}$ & A & -- & $\mathbf{0 , 0 0 ~ K M}$ \\
2. & & B & A - B & $\mathbf{6 , 8 0 ~ K M}$
\end{tabular}

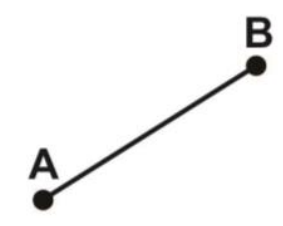

3.

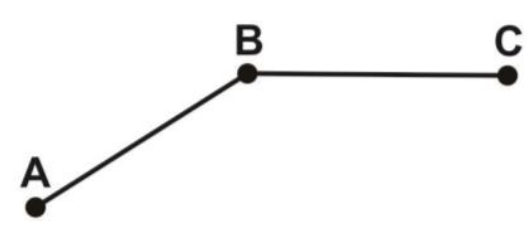

4.

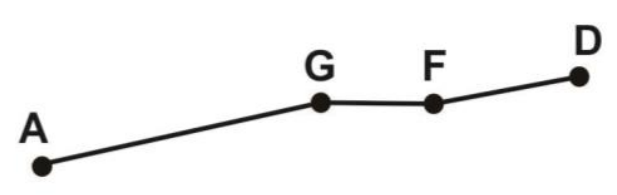

5.

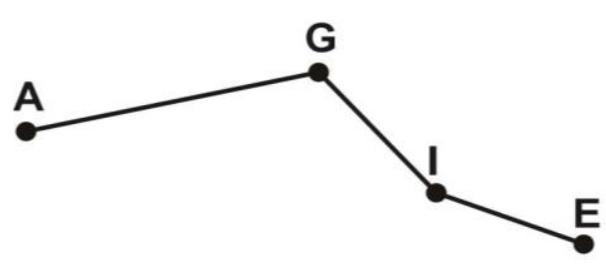

6.

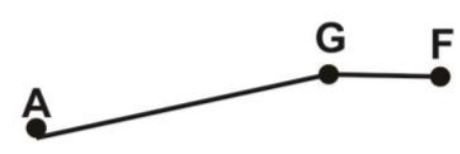

7.

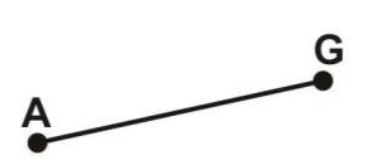

C

$\mathbf{A}-\mathbf{B}-\mathbf{C}$

$8,70 \mathrm{KM}$

D

A - G - F - D

8,60 KM

E

$\mathbf{A}-\mathbf{G}-\mathbf{I}-\mathbf{E}$

11,20 KM

F

A - G - F

7,50 KM

G

A - G

7,10 KM 
8.

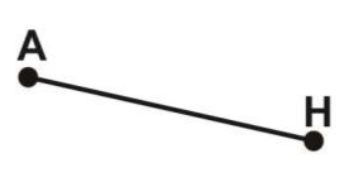

9.

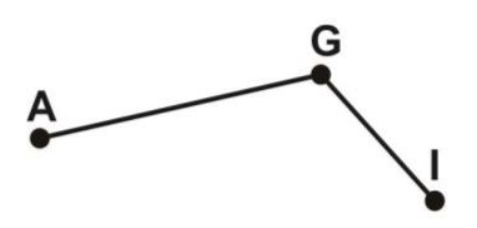

10.

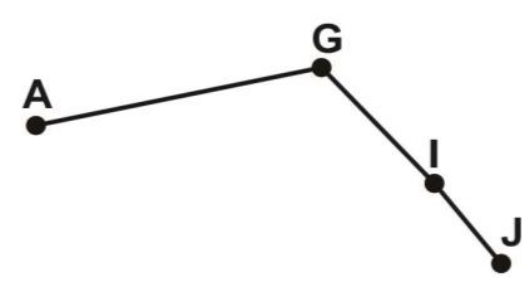

11.

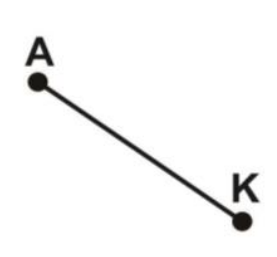

H

A- $\mathbf{H}$

9,90 KM

I

A - G - I

$10,00 \mathrm{KM}$

J

$\mathbf{A}-\mathbf{G}-\mathbf{I}-\mathbf{J}$

$10,75 \mathrm{KM}$

K

A - K

$10,00 \mathrm{KM}$

Hasil pada Tabel 2 memberikan hasil rute terpendek dari titik awal ke semua pasangan titik. Berikut adalah hasil dari perhitungan secara manual penentuan rute terpendek dengan Algoritma Djikstra dengan Terminal Delanggu sebagai titik awal disajikan pada Tabel 3.

Tabel 3. Rute terpendek tempat wisata air yang ada di Klaten dengan titik awal Terminal Delanggu

\begin{tabular}{|c|c|c|c|c|}
\hline No. & Titik awal & Tujuan & Rute & Jarak \\
\hline 1. & Terminal Delanggu & $\begin{array}{c}\text { Objek Wisata } \\
\text { Mata Air Cokro }\end{array}$ & $\begin{array}{c}\text { Terminal Delanggu - Objek Wisata } \\
\text { Mata Air Cokro }\end{array}$ & $6,80 \mathrm{KM}$ \\
\hline 2. & Terminal Delanggu & Umbul Ponggok & $\begin{array}{l}\text { Terminal Delanggu - Objek Wisata } \\
\text { Mata Air Cokro - Umbul Ponggok }\end{array}$ & $8,70 \mathrm{KM}$ \\
\hline 3. & Terminal Delanggu & Umbul Besuki & $\begin{array}{l}\text { Terminal Delanggu - Wisata Air } \\
\text { Water Gong Polanharjo - Umbul } \\
\text { Sigedang - Umbul Besuki }\end{array}$ & $8,60 \mathrm{KM}$ \\
\hline 4. & Terminal Delanggu & Umbul Nilo & $\begin{array}{l}\text { Terminal Delanggu - Wisata Air } \\
\text { Water Gong Polanharjo - Umbul } \\
\text { Pelem Water Park - Umbul Nilo }\end{array}$ & $11,20 \mathrm{KM}$ \\
\hline 5. & Terminal Delanggu & $\begin{array}{l}\text { Umbul } \\
\text { Sigedang }\end{array}$ & $\begin{array}{c}\text { Terminal Delanggu - Wisata Air } \\
\text { Water Gong Polanharjo - Umbul } \\
\text { Sigedang }\end{array}$ & 7,50 KM \\
\hline 6. & Terminal Delanggu & $\begin{array}{l}\text { Wisata Air } \\
\text { Water Gong } \\
\text { Polanharjo }\end{array}$ & $\begin{array}{l}\text { Terminal Delanggu - Wisata Air } \\
\text { Water Gong Polanharjo }\end{array}$ & $7,10 \mathrm{KM}$ \\
\hline 7. & Terminal Delanggu & Umbul Manten & Terminal Delanggu - Umbul Manten & 9,90 KM \\
\hline 8. & Terminal Delanggu & Umbul Pelem & Terminal Delanggu - Wisata Air & $10,00 \mathrm{KM}$ \\
\hline
\end{tabular}




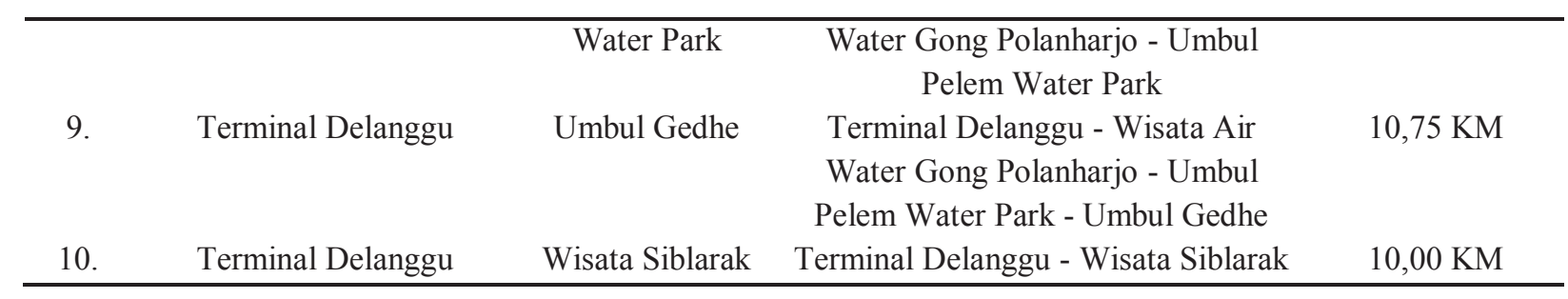

Untuk mengecek nilai perhitungan secara manual digunakan software Tora dimana pada software tersebut sudah ada paket Algoritma Djikstra. Gambar 2 merupakan output software Tora rute terpendek tempat wisata air di Klaten dengan titik awal Terminal Delanggu.

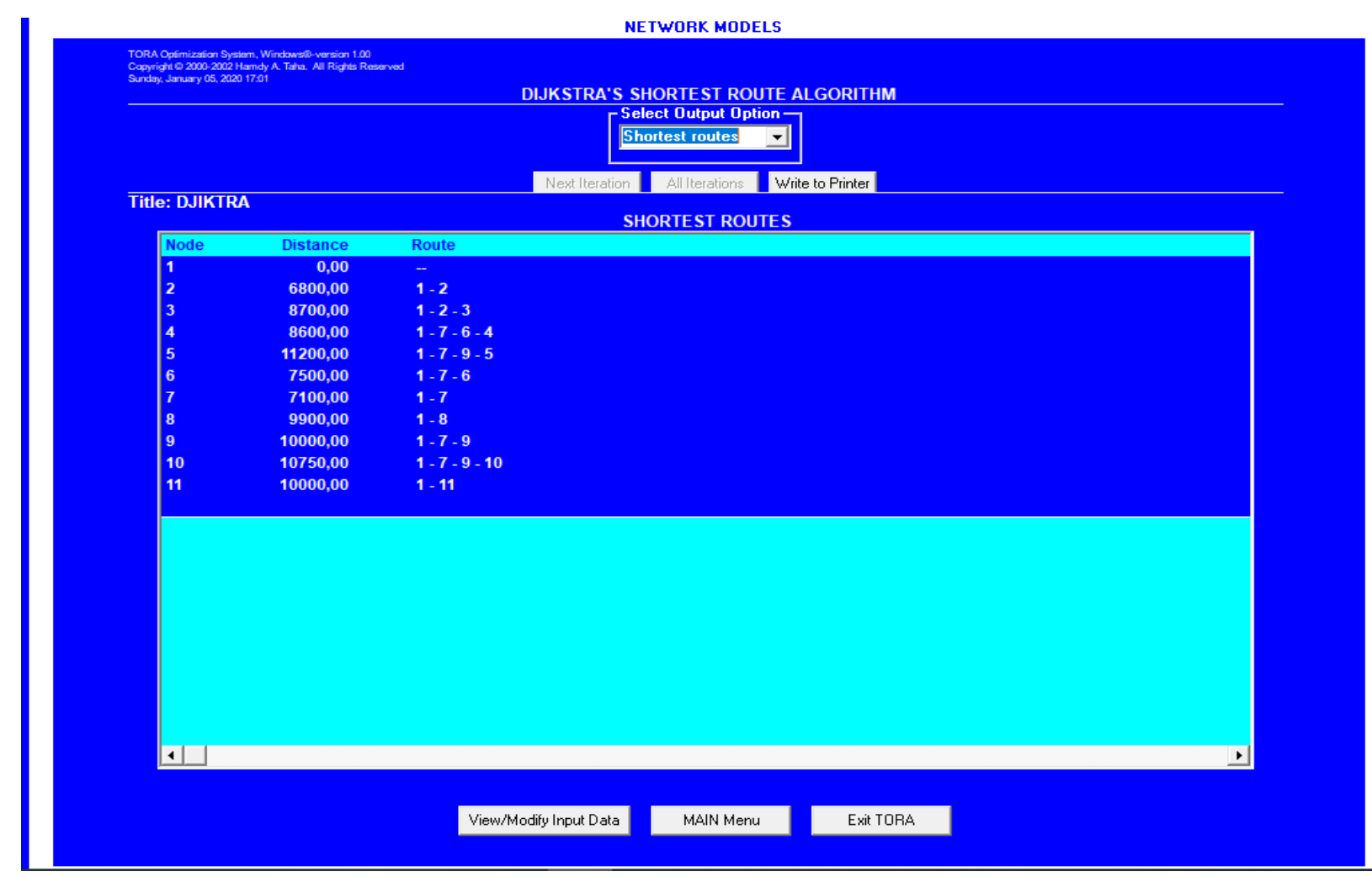

Gambar 2. Output software Tora rute terpendek tempat wisata air yang ada di Klaten dengan titik awal Terminal Delanggu

Software Tora pada Gambar 2 mendapatkan hasil akhir seperti dalam perhitungan rute terpendek pada algoritma Djikstra. Hasil output dari rute terpendek secara manual pada Tabel 3 dan dengan menggunakan software Tora seperti Gambar 2, dari hasil perhitungan tersebut diperoleh hasil yang sama. Dengan demikian, algoritma Dijkstra dapat digunakan dalam pencarian rute terpendek tempat wisata di Kabupaten Klaten.

Hasil penelitian ini menunjukkan bahwa ada sepuluh jalur terpendek dari titik awal Terminal Delanggu ke setiap objek wisata. Pada jalur tersebut terlihat bahwa tidak semua rute terpendek berbeda, sehingga untuk menuju satu tujuan wisata dapat melalui tujuan wisata 
lain. Oleh karena itu, dapat dibuat suatu paket wisata yang di dalam satu paket wisata tersebut dalam satu rute terdapat beberapa objek wisata (Sudana, 2016). Sebagai contoh, paket wisata Umbul Gedhe dari Terminal Delanggu dalam satu hari bisa mengunjungi Wisata Air Water Gong Polanharjo, Umbul Pelem Water Park dan Umbul Gedhe.

\section{SIMPULAN}

Penelitian yang telah dilakukan menemukan dan menyimpulkan sebagai berikut. Algoritma Dijkstra dapat digunakan dalam pencarian rute terpendek tempat wisata di Kabupaten Klaten. Dari hasil perhitungan yang secara manual dan yang menggunakan software Tora, diperoleh hasil yang sama.

\section{UCAPAN TERIMA KASIH}

Universitas Duta Bangsa yang telah mendanai dan mendukung penelitian ini.

\section{DAFTAR PUSTAKA}

Ardyan, S., Suyitno, A., \& Mulyono. (2017). Implementasi Algoritma Dijkstra Dalam Pencarian Rute Terpendek Tempat Wisata Di Kabupaten. UNNES Journal of Mathematics, 6(2), 108-116.

EPP, S. S. (2011). Discrete Mathematics With Applications (fourth). Canada: Richard Stratton.

Fitria, \& Triansyah, A. (2013). Implementasi Algoritma Dijkstra Dalam Aplikasi Untuk Menentukan Lintasan Terpendek Jalan Darat Antar Kota Di Sumatera Bagian Selatan. Jurnal Sistem Informasi (JIS), 5(2), 611-621. Retrieved from http://ejournal.unsri.ac.id/index.php/jsi/article/download/840/430

Harahap, M. K., \& Khairina, N. (2017). Pencarian Jalur Terpendek dengan Algoritma Dijkstra. SinkrOn, 2(2), 18. https://doi.org/10.33395/sinkron.v2i2.61

Prajapati, G. L., Singhal, P., Ranjan, A., \& Chourasia, N. (2017). An Efficient Scheme for the Single Source Shortest Path Problem based on Dijkstra and SPFA Methodologies. International Journal of Computer Applications, 163(8), 46-52. https://doi.org/10.5120/ijca2017913694

Retnani, W. E. Y., Istiadi, D., \& Roqib, A. (2015). Pencarian SPBU Terdekat dan Penentuan Jarak Terpendek Menggunakan Algoritma DIJKSTRA (Studi Kasus di Kabupaten Jember). Jurnal Nasional Teknik Elektro, 4(1), 89. https://doi.org/10.25077/jnte.v4n1.132.2015 
Sholihah, S. U. (2015). Penggunaan Algoritma Dijkstra dalam penentuan jalur alternatif untuk mengurangi kemacetan lalulintas. Institut Teknologi Bandung, 2(2), 90-99.

Sudana, I. P. (2016). PENGEMASAN PAKET WISATA CITY TOUR BERBASIS BUDAYA DI KOTA DENPASAR BALI I Wayan Gede Ary Mahendra Putra I Made Kusuma Negara Puri Pemecutan memiliki keunikan pada arsitekturnya yang bergaya traditional Bali. $4(1), 6-12$.

Wang, S. X. (2012). The improved Dijkstra's shortest path algorithm and its application. Procedia Engineering, 29, 1186-1190. https://doi.org/10.1016/j.proeng.2012.01.110

Yusuf, M. S., Az-zahra, H. M., \& Apriyanti, D. H. (2017). Implementasi Algoritma Dijkstra Dalam Menemukan Jarak Terdekat Dari Implementasi Algoritma Dijkstra Dalam Menemukan Jarak Terdekat Dari Lokasi Pengguna Ke Tanaman Yang Di Tuju Berbasis Android (Studi Kasus di Kebun Raya Purwodadi). Jurnal Pengembangan Teknologi Informasi Dan Ilmu Komputer, 1(August), 1779-1781. 